\title{
Penerapan Algoritma Aprioti Pada Riwayat Data Kecelakaan Lalu Lintas
}

\author{
Yusup Miftahuddin $^{1^{*}}$ Faza Muhammad Raihan ${ }^{2}$ \\ 1,2 Program Studi Informatika, Institut Teknologi Nasional Bandung \\ ${ }^{1}$ yusufm@itenas.ac.id
}

\begin{abstract}
Abstrak
Dengan meningkatnya pengguna kendaraan bermotor,kecelakaan lalu lintas juga akan semakin rentan terjadi.Salah satu cara agar meminimalisir terjadinya kecelakaan lalu lintas adalah dengan cara mengolah riwayat data kecelakaan menggunakan teknik data mining. Teknik ini bertujuan untuk menemukan informasi pola hubungan kecelakaan lalu lintas yang dapat membantu mengetahui penyebab - penyebab utama terjadinya kecelakaan lalu lintas.Teknik data mining yang digunakan adalah teknik association rule dengan algoritma Apriori.Pada metode tersebut tahap analisis yang sering dilakukan banyak peneliti untuk menghasilkan algoritma Apriori yang efisien yaitu analisis pola frekuensi suatu asosiasi dapat diketahui dengan dua faktor pada metode terebut yaitu Support dan Confidence.Pada saat ini,mengukur nilai minimum support pada algoritma Apriori masih ditentukan oleh user,dengan begitu penentuan nilai minimum support akan berulang - ulang oleh user hingga mencapai nilai korelasi positif. Hasil penelitian ini menerapkan metode untuk menentukan nilai minimum support dengan hasil akhir semua data mendapat korelasi positif sebagai acuan nilai lift ratio $>1$ serta mendapatkan 6 pola kecelakaan lalu lintas yang paling sering terjadi.
\end{abstract}

Kata Kunci: kecelakaan lalu lintas,asosiasi data,apriori, minimum support.

\begin{abstract}
With the increase of vehicle users, traffic accidents tend to happen more often. One of many ways to minimize the occurrence of traffic accidents is to process accident data history using data mining techniques. This technique is utilized in order to gain information regarding the relational pattern of traffic accidents. The data mining technique used is the association rule technique with the Apriori algorithm. One of the stages of analysis that has attracted the eyes of many researches to produce an efficient Apriori algorithm is analyzing the frequency pattern of an association that can be identified with two benchmarks; Support and Confidence. Currently, the determination of the minimum support value will be repeated by the user until it reaches a positive correlation value. This study applies a certain method to determine the minimum support value with the final result of achieving positive correlation on all datas as a reference for the lift ratio value $>1$ and getting 6 of the most frequent traffic accident patterns.
\end{abstract}

Keyword: traffic accident, association rule, apriori,minimum support.

\section{Pendahuluan}

Menurut World Health Organization(WHO), kecelakaan lalu lintas merupakan penyebab kematian terbesar diantara umur 15 hingga 29 tahun pada Negara dengan tingkat pendapatan rendah dan menengah[1][2]. Salah satu cara untuk mengetahui pola suatu kecelakaan lalu lintas adalah dengan menggunakan teknik data mining metode algoritma Apriori.Algoritma Apriori termasuk jenis aturan asosiasi data pada data mining yang bertujuan untuk menemukan frequent item sets dijalankan pada sekumpulan 
data.Hasil analisisnya didefinisikan suatu proses menemukan aturan apriori yang memenuhi syarat nilai minimum support dan nilai confidence[3]. Algoritma Apriori dapat melakukan penggalian data untuk menentukan pola kecelakaan lalu lintas secara baik tetapi algoritma Apriori memiliki kelemahan salah satunya adalah pemrosesannya yang cukup lama, pada saat ini, untuk menentukan nilai minimum support masih dilakukan manual oleh user.Penelitian mengusulkan metode untuk menentukan nilai minimum support dimana sebelum terjadinya perhitungan apriori dataset akan dihitung terlebih dahulu untuk mencari threshold support pada dataset tersebut. [4]

Berdasarkan pemaparan tersebut, bahwa proses data mining untuk mengetahui pola kecelakaan lalu lintas sangat diperlukan, dikarenakan setiap riwayat data memiliki informasi yang berharga sebagai acuan penyebab utama kecelakaan lalu lintas serta pada proses pencarian informasinya diperlukan waktu yang lebih singkat[5]. Pada penelitian ini metode algoritma Apriori digunakan sebagai pencarian pola kecelakaan lalu lintas dan menerapkan metode untuk menentukan nilai minimum support pada proses tersebut.

\section{Tinjauan Pustaka}

\subsection{Penelitian Terkait}

Pada penelitian sebelumnya penentuan pola kecelakaan lalu lintas dengan menggunakan teknik data mining yaitu association rule dengan Algoritma Fp-growth. Algoritma ini menerapkan struktur data tree untuk mengetahui pola kecelakaan lalu lintas.Hasil akhir menunjukan melalui uji lift ratio dengan nilai $1.20 \%$ didapatkan pola kecelakaan lalu lintas yang paling sering terjadi yaitu jenis_luka adalah luka ringan, jenis_jalan adalah jalan arteri[6].Penelitian pembuatan pola kecelakaan lalu lintas di $\mathrm{Jl}$. Ahmad Yani Surabaya meliputi analisa situasi, identifikasi blackspot, faktor pemicu dan karakteristik kecelakaan dengan menggunakan pendekatan Knowlede Discovery in Database Hasil analisa menunjukan peningkatan angka kecelakaan disebabkan oleh faktor kedisiplinan pengguna jalan[7].Penelitian mengenai Algoritma apriori pernah menggunakan data resmi dari pemerintah Uni Arab Emirat. Penelitian tersebut berfokus pada kasus seringnya terjadi kecelakaan pada hari - hari weekend.Hasil penelitian menunjukan penyebab utama terjadinya kecelakaan lalu lintas adalah kendaraan yang menabrak kendaraan lain dikarenakan ruang yang tidak memadai dan hasil lainnya adalah pengendara yang usianya masih muda dan insidennya terjadi pada malam hari[1].

Penelitian dengan menggunakan algoritma Apriori dapat digunakan juga untuk sebuah penjualan barang, penelitian menggunakan data penjualan sepatu untuk mengetahui hubungan frekuensi penjualan sepatu yang paling diminati oleh konsumen, dengan hasil penelitian sepatu dengan nilai teratas atau yang paling diminati yaitu new balance $(91,67 \%)$, Adidas (75 \%), Geox (50 
\%),dan Nike (41.67\%) [8].Penelitian mengenai pembayaran kredit dilakukan menggunakan Agoritma Decision Tree untuk memberikan beberapa opsi untuk melihat faktor apa yang menjadi kredit macet atau lancar.Pengujian dilakukan sebanyak 9 kali yaitu validation 2 sampai dengan 10 maka didapatkan dua hasil akurasi terbaik dari K-Fold Validation 9 dan K-Fold Validation 10 masing-masing memiliki nilai accuracy sebesar $96,43 \%$ pada K-Fold Validation 9 dan 96,45\%[9].Penelitian dengan menggunakan data mining dengan menggunakan metode $K$ Means dilakukan dengan tema pengklasteran penduduk miskin dimana metode Algoritma KMeans Clustering ini bertujuan untuk mengelompokkan data penduduk di wilayah Sukamulia Timur. Hasil pengujian yang dilakukan dengan menerapkan algoritma K-Means didapatkan hasil dengan Cluster 1 berjumlah 18 penduduk dengan kriteria Penduduk ekonomi tinggi, Cluster 2 berjumlah 72 Penduduk dengan kriteria Penduduk ekonomi sedang, dan Cluster 3 berjumlah 110 penduduk dengan kriteria Penduduk ekonomi rendah[10].Metode algoritma Apriori memiliki kelemahan salah satunya yaitu penentuan nilai minimum support yang masih dilakukan secara manual oleh user,maka dari itu penelitian dilakukan ,penelitian tersebut memaparkan metode untuk menentukan nilai minimum support berdasarkan karakteristik dataset pada asosiasi data.Hasil penelitian menunjukan 6 dari 8 datasets memiliki aturan nilai lift ratio $>1$ hasil dari menggunakan nilai minimum threshold berdasarkan metode penentuan nilai minimum support[4].

\subsection{Landasan Teori}

Pada pembangunan sistem menggunakan teori sebagai penunjang antara lain:

\section{Data Mining}

Definisi umum data mining adalah proses pencarian pola-pola tersembunyi (hidden pattern) berupa pengetahuan (knowledge) yang belum diketahui sebelumnya pada sekumpulan data yang dapat berada pada database atau media penyimpanan lainnya[11]. Istilah data mining dan knowledge discovery in databases (KDD) sering kali digunakan secara bergantian untuk menjelaskan proses penggalian informasi tersembunyi dalam suatu basis data Principle besar. Sebenarnya kedua istilah tersebut memiliki konsep yang berbeda, tetapi berkaitan satu sama lain. Dan salah satu tahapan pada proses KDD yaitu data mining[12]. Proses KDD secara garis besar dapat dijelaskan menjadi beberapa tahap sebagai berikut:

- Data Selection, proses pemilihan data yang akan digunakan dan disimpan di sebuah wadah

- Data Cleaning, proses dimana rule yang tidak lengkap, mengandung error, dan tidak konsisten dibuang dari knowledgei data. 
- Data Transformation,tahapan ini melakukan attribute contraction yaitu melakukan pembagian data menjadi beberapa area.

- Data mining, proses mencari pola atau informasi menarik dalam knowledge terpilih dengan menggunakan teknik atau metode tertentu.

- Interpretation, Pola informasi atau rule information yang dihasilkan dari proses data mining perlu ditampilkan dalam bentuk informasi yang mudah dimengerti oleh pihak yang berkepentingan.Tahap ini merupakan proses interpretation dalam bagian proses KDD.

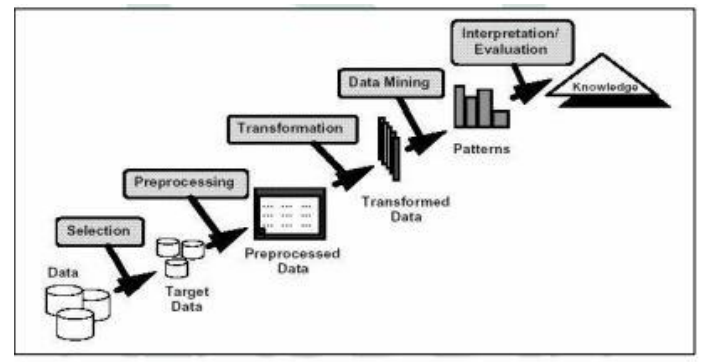

Gambar 1. Alur Knowledge Discovery in Databases

\section{Algoritma Apriori}

Algoritma Apriori merupakan salah satu dari sekian banyak metode yang secara luas digunakan untuk mencari di database yang besar[1]. Metode tersebut memiliki aturan asosiasi data(Association rule) untuk menentukan hubungan asosiatif pada antar item[13]. Association rule disini merujuk pada mekanisme perhitungan nilai support dan confidence dari suatu hubungan item.Sebuah nilai dikatakan interesting jika nilai support diatas nilai minimum support begitu juga dengan nilai confidence.

3. Penentuan Nilai Minimum Support

Konsep dasar aturan asosiasi mengharuskan user untuk menentukan nilai minimum support di awal. Nilai ini biasanya selalu sama untuk semua item, meskipun pada kenyataannya, item yang berbeda mungkin memiliki kriteria yang berbeda untuk menilainya[4].Minimum Support merupakan nilai ambang batas mimimum pada sejumlah itemset yang diperbolehkan,jika nilainya dibawah ambang batas bawah maka itemset tersebut akan di bersihkan.Penentuan nilai minimum support dapat dilakukan dengan tahapan - tahapan rumus berikut.

- Perhitungan nilai support untuk setiap item dalam dataset

$$
\sup (d)=\frac{n(d)}{|D|}
$$

- Perhitungan nilai utility untuk setiap item dalam dataset

$$
\operatorname{Util}(D)=\operatorname{Sup}(d) X U(d)
$$

- Perhitungan nilai rata-rata utility

$$
\text { ave sup }=\frac{\sum U \text { til }(\mathrm{d})}{|\mathrm{D}|}
$$

- Perhitungan nilai threshold yang digunakan sebagai nilai akhir minimum support

$$
\min \sup =\frac{\text { ave sup }}{|D|}
$$

Keterangan:

Sup(d): nilai support pada item

$\mathrm{n}(\mathrm{d})$ : jumlah transaksi pada item 
$|D|$ : total transaksi

$\mathrm{U}(\mathrm{d})$ : nilai utility pada item

Util(d): nilai utility dan nilai support pada item

Avesup = nilai rata-rata utility pada item

Minsup $=$ nilai threshold minimum support.

\section{Analisis Pola Frekuensi Tinggi}

Tahap ini merupakan sebuah metode untuk mencari kombinasi item yang memenuhi syarat nilai minimum support dan nilai confidence[14].Proses ini merupakan tahap awal dari data mining metode algoritma Apriori,diperoleh dengan rumus berikut.

Support $(A)=\sum \frac{\text { Transaksi mengandung A }}{\text { Transaksi }} \times 100 \%$

Nilai support dari 2 item diperoleh dengan menggunakan rumus.

$$
\begin{aligned}
& \text { Support }(A, B)=P(A \cap B) \\
& \text { Support }(A, B)=\sum \frac{\text { transaksi mengandung }(A, B)}{\text { Transaksi }} \times 100 \%(5)
\end{aligned}
$$

Keterangan:

Support(A): Nilai support A pada item.

Support( $A, B)$ : Nilai support $A$ dan $B$ pada item.

\section{Pembentukan Aturan Asosiasi}

Setelah tahap pencarian support,selanjutnya adalah proses pembentukan aturan asosiasi yang memenuhi syarat minimum confidence aturan asosiatif dimana A U B.Nilai confidence pada A U $B$ diperoleh dengan rumus berikut.

Confidence $P(B \mid A)=\frac{\sum \text { Transaksi mengandung } A \text { dan } B}{\sum \text { Transaksi mengandung } A}(6)$

Keterangan:

Confidence $\mathrm{P}(\mathrm{B} \mid \mathrm{A})$ : Nilai confidence pada itemset.

6. Lift Ratio
Lift ratio merupakan metode untuk mengukur seberapa penting rule yang telah terbentuk berdasarkan nilai support dan confidence. Lift Ratio adalah perbandingan Antara nilai confidence dan benchmark confidence[15][16]. Pada pengujiannya memiliki rumus sebagai berikut.

Lift Ratio $=\frac{\text { Confidence }(A, B)}{\text { benchmark confidence }(A, B)}$

\section{Metode Penelitian}

Metodologi yang digunakan dalam penelitian ini (4) adalah sebagai berikut:

1. Pemahaman Terhadap Bisnis (Business Understanding)

Bisnis dalam penelitian ini merujuk terhadap pemahaman penelitian dengan melakukan analisis faktor - faktor yang menyebabkan kecelakaan lalu lintas terhadap suatu dataset yang akan diteliti.

2. Pemahaman Terhadap Data(Data Understanding)

Terdapat 2766 data kecelakaan lalu lintas yang diambil langsung dari situs pemerintahan britania raya dalam bentuk format CSV dengan alamat situs https://data.gov.uk/ dengan jumlah atribut berjumlah 15. Pada tahap awal,dataset riwayat data kecelakaan lalu lintas akan digunakan sebagai nilai input pada proses KDD.Tahap-tahap KDD seperti data selection,data cleaning, dan data transform akan dilakukan secara 
manual,fokus penelitian disini dimulai dari proses data mining dengan metode algoritma Apriori dan pada tahap ini juga dilakukan implementasi metode untuk menentukan nilai minimum support,menentukan pola kecelakaan lalu lintas berdasarkan nilai support dan confidence serta melakukan uji nilai lift ratio sebagai representasi nilai keakuratan metode penentuan nilai minimum support.Tahap akhir yaitu interpretation akan di implementasikan pada aplikasi berbasis web sebagai media interpresentasinya.Dalam memahami sebuah data diperlukan alur tahapan penelitian salah satu caranya adalah dengan membuat blok diagram,berikut adalah rancangan sistem yang dibangun dengan menggunakan blok diagram digambarkan pada Gambar 2.

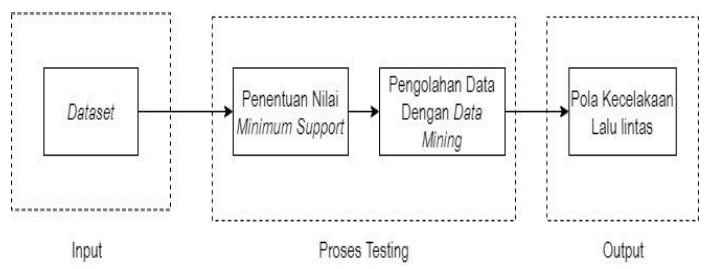

Gambar 2. Blok Diagram Sistem

Berdasarkan Gambar 2,terdapat beberapa poin yang akan dijelaskan, untuk penjelasannya sebagai berikut:

- Input berupa dataset dari riwayat kecelakaan lalu lintas yang telah dirancang agar dapat langsung diproses menuju pengolahan data mining tanpa perlu melalui proses awal dari KDD.

- Proses Testing terdiri dari proses penentuan nilai minimum support dan proses pengolahan data mining dengan menggunakan metode algoritma Apriori.
- Output menggambarkan pola kecelakaan lalu lintas berdasarkan dataset yang telah di input.

3. Persiapan Data(Data Preparation)

Pada tahap ini data akan diseleksi untuk menghasilkan data yang dibutuhkan untuk penelitian ini,tahapannya antara lain adalah:

- Data Cleaning,proses ini dilakukan untuk menghilangkan noise pada dataset dengan tujuan untuk mengurangi redudansi data.

- Data Integration, berfungsi sebagai proses untuk menyatukan data pada satu media penyimpanan yang berbeda dalam satu data.Dalam hal ini data disimpan dalam satu tempat penyimpanan namun dipisahkan berdasarkan tanggal,bulan, dan tahun,maka dengan ini, tahapan semua data pertahun disatukan.

- Data Reduction,pada penelitian ini data akan dikurangi hingga menjadi 1000 data dan atribut yang tidak diperlukan akan dihapus sehingga atribut yang digunakan menjadi 5 atribut.

\section{Hasil dan Pembahasan}

Penelitian menggunakan dataset yang diambil dari website pemerintahan britania raya dengan alamat website yaitu https://data.gov.uk/, berupa data riwayat kecelakaan lalu lintas dengan jumlah data yang dipakai sebanyak 1000 data dan terdiri dari 5 atribut Antara lain yaitu " 1 st Road Class","Road Surface", "Lighting Condition", "Weather Conditions",dan "Type of Vehicle". Penelitian terdiri dari 3 tahapan sebagai berikut. 
1. Penentuan Nilai Minimun Support

Tabel 1. Hasil Nilai Support item

\begin{tabular}{llll}
\hline No & Item & Jumlah & Support \\
\hline 1 & Unclassified & 473 & 47.3 \\
\hline 2 & Wet / Damp & 230 & 23 \\
\hline 3 & Darkness & 262 & 26.2 \\
& $\begin{array}{l}\text { street lights } \\
\text { present and }\end{array}$ & \\
& lit \\
\hline 4 & $\begin{array}{l}\text { Snowing } \\
\text { without high }\end{array}$ & \\
& winds & \\
& & \\
\hline 5 & Car & 708 & 70.8 \\
\hline
\end{tabular}

- Rumus perhitungan nilai support untuk setiap item dalam dataset:

$\sup (\mathrm{Car})=\frac{\mathrm{n}(\mathrm{d})}{|\mathrm{D}|}=\frac{708}{1000}=70.8$

Total item pada dataset tersebut berjumlah 36 item, lima data item teratas ditampilkan pada tabel1.

- Rumus perhitungan nilai utility untuk setiap item dalam dataset.Pada penelitian ini user memberi nilai $\mathrm{U}(\mathrm{d})=5000$, nilai 5000 diambil dari total jumlah item pada dataset.

Util(Car) $=\operatorname{Sup}(d) X U(d)=70.8 \times 5000=35400$

Semua item dihitung nilai utility nya selanjutnya nilai utility dijumlahkan untuk proses selanjutnya.

- Rumus perhitungan nilai rata-rata utility.Total nilai utility pada dataset berjumlah 2500000 .

ave sup $=\frac{\sum \text { Util }(\mathrm{d})}{|\mathrm{D}|}=\frac{2500000}{1000}=2500$
- Rumus perhitungan nilai threshold yang digunakan sebagai nilai akhir minimum support. min sup $=\frac{\text { ave sup }}{|D|}=\frac{2500}{1000}=2.5 \%$ Hasil akhir menunjukan bahwa nilai minimum support pada dataset riwayat kecelakaan lalu lintas adalah $2.5 \%$ dari jumlah item yaitu 5000 data yang berarti nilai minimum support yang ditetapkan adalah 125 .

\section{Pengujian Algoritma Apriori}

Pada pengujian ini,pembentukan pola kecelakaan lalu lintas dilakukan.Tahap awal dalam proses ini adalah menentukan nilai minimum support dan confidence,untuk nilai minimum support adalah 125 dan nilai confidence adalah 95\%.Nilai minimum support diambil dari penentuan nilai minimum support pengujian sebelumnya.

Tabel 2. Hasil Asosiasi

\begin{tabular}{lll}
\hline Aturan & $\begin{array}{l}\text { Sup } \\
\text { port }\end{array}$ & \multicolumn{1}{c}{$\begin{array}{l}\text { Confi } \\
\text { dence }\end{array}$} \\
\hline Jika kondisi Dry dan & $33,20 \%$ & $98,52 \%$ \\
Unclassified, maka & & \\
kondisi Fine without high & & \\
winds & & \\
\hline Jika kondisi Darkness: & $12,90 \%$ & $99,23 \%$ \\
street lights present and \\
lit, Dry, maka kondisi \\
Fine without high winds \\
Jika kondisi Car, Dry, & & \\
maka kondisi & Fine & \\
without high winds & & \\
\hline
\end{tabular}




\begin{tabular}{l} 
Jika kondisi Dry, A, maka 28,00\% $98,94 \%$ \\
kondisi Fine without high \\
winds \\
\hline Jika kondisi Dry , 54,60\% $98,56 \%$ \\
Daylight: street lights \\
present, maka kondisi \\
Fine without high winds \\
Jika kondisi Dry, maka $69,50 \% \quad 98,58 \%$ \\
kondisi Fine without high \\
winds
\end{tabular}

Hasil akhir menunjukan 6 pola hubungan kuat terbentuk pada riwayat data kecelakaan lalu lintas,pada tabel 2 nilai confidence tertinggi yaitu 99,23\% dengan kondisi pola jika kecelakaan pada malam hari dengan kondisi penerangan yang layak dan kondisi jalan yang kering,maka kemungkinan kecelakaan terjadi juga dengan kondisi cuaca yang cerah tanpa angin yang kencang.

\section{Pengujian Nilai Lift Ratio}

Pada penelitian ini pengujian nilai lift Ratio digunakan untuk mengukur seberapa penting Rule yang terbentuk berdasarkan support dan confidence sebelumnya.Berikut merupakan hasil uji nilai lift ratio dipaparkan pada tabel 3.

Tabel 3. Pengujian Nilai Lift Ratio

\begin{tabular}{lll}
\hline $\mathbf{X}=>\mathbf{Y}$ & $\begin{array}{l}\text { Confi } \\
\text { dence }\end{array}$ & $\begin{array}{l}\text { Uji } \\
\text { Lift } \\
\text { Ratio }\end{array}$ \\
\hline $\begin{array}{l}\text { Dry , Unclassified => Fine } \\
\text { without high winds }\end{array}$ & $98,52 \%$ & 1,13 \\
\hline
\end{tabular}

\begin{tabular}{lll}
\hline $\begin{array}{l}\text { Darkness: street lights } \\
\text { present and lit , Dry }=>\end{array}$ & $99,23 \%$ & 1,14 \\
Fine without high winds & & \\
\hline $\begin{array}{l}\text { Car, Dry => Fine without } \\
\text { high winds }\end{array}$ & $98,77 \%$ & 1,14 \\
\hline $\begin{array}{l}\text { Dry , A => Fine without } \\
\text { high winds }\end{array}$ & $98,94 \%$ & 1,14 \\
\hline $\begin{array}{l}\text { Dry, Daylight: street lights } \\
\text { present => Fine without } \\
\text { high winds }\end{array}$ & $98,56 \%$ & 1,13 \\
\hline $\begin{array}{l}\text { Dry => Fine without high } \\
\text { winds }\end{array}$ & $98,58 \%$ & 1,13 \\
\hline
\end{tabular}

Hasil akhir menunjukan semua itemsets menunjukan korelasi positif dengan acuan nilai lift ratio $>1$.

\section{Kesimpulan}

Berdasarkan hasil uji coba ditarik kesimpulan sebagai berikut:

1. Proses data mining dengan menggunakan metode algoritma Apriori menghasilkan pola hubungan kuat Antara faktor-faktor terjadinya kecelakaan lalu lintas dengan ditemukannya 6 pola hubungan kuat pada penelitian ini.

2. Penerapan metode penentuan nilai minimum support dapat menghemat waktu dalam proses pengerjaan sistem data mining dengan hasil uji lift ratio menunjukan semua pola menunjukan korelasi positif.

3. Orang yang berkepentingan dalam penanganan kecelakaan lalu lintas dapat mengevaluasi penanganan kecelakaan lalu lintas dengan lebih efektif. 


\section{Daftar Pustaka}

[1] M. John and H. Shaiba, "Apriori-Based Algorithm for Dubai Road Accident Analysis," Procedia Comput. Sci., vol. 163, pp. 218227, 2019, doi: 10.1016/j.procs.2019.12.103.

[2] R. N. D. C. Ratu, A. Pamuttu, and J. B. Bension, "Karakteristik Dan Pola Luka Korban Kecelakaan Lalu Lintas Di Rumah Sakit Bhayangkara Ambon Periode 20142017," Molucca Medica, vol. 14, no. April, pp. 63-69, 2021, doi: 10.30598/molmed.2021.v14.i1.63.

[3] A. Nursikuwagus and T. Hartono, "Implementasi Algoritma Apriori Untuk Analisis Penjualan Dengan Berbasis Web," Simetris J. Tek. Mesin, Elektro dan IImu Komput., vol. 7, no. 2, p. 701, 2016, doi: 10.24176/simet.v7i2.784.

[4] E. Hikmawati, N. U. Maulidevi, and K. Surendro, "Minimum threshold determination method based on dataset characteristics in association rule mining," J. Big Data, vol. 8, no. 1 , p. 146, Dec. 2021, doi: 10.1186/s40537-021-00538-3.

[5] A. Sudianto and M. Wasil, "Penerapan Sistem Informasi Geografis dalam Pemetaan Sebaran Kasus Gizi Buruk Lombok Timur merupakan salah satu Kabupaten yang berada di Provinsi Nusa Tenggara Barat yang terletak di sebelah Timur Pulau Lombok , Kabupaten Lombok Timur Gizi Buruk Malnutrisi," vol. 4, no. 2, pp. 142-150, 2021.
[6] R. Fitria, W. Nengsih, and D. H. Qudsi, "Implementasi Algoritma FP-Growth Dalam Penentuan Pola Hubungan Kecelakaan Lalu Lintas," J. Sist. Inf., vol. 13, no. 2, p. 118, 2017, doi: 10.21609/jsi.v13i2.551.

[7] A. Zanuardi and H. Suprayitno, "Analisa Karakteristik Kecelakaan Lalu Lintas di Jalan Ahmad Yani Surabaya melalui Pendekatan Knowledge Discovery in Database," J. Manejemen Aset Infrastruktur Fasilitas, vol. 2, no. 1, pp. 45-55, 2018, doi: 10.12962/j26151847.v2i1.3767.

[8] E. D. Sikumbang, "Penerapan Data Mining Penjualan Sepatu Menggunakan Metode Algoritma Apriori," J. Tek. Komput. AMIK BSI, vol. Vol 4, No., no. September, pp. 1-4, 2018.

[9] M. Mahpuz, Y. Yahya, and M. Wasil, "Implementasi Algoritma Decision Tree Untuk Mengetahui Faktor Kredit Macet Dan Lancar Di Koperasi Serba Usaha Daruzzakah Rensing Lombok Timur," Infotek J. Inform. dan Teknol., vol. 3, no. 2, pp. $92-$ 103, Aug. 2020, doi: 10.29408/jit.v3i2.2299.

[10] S. Suhartini and R. Yuliani, "Penerapan Data Mining untuk Mengcluster Data Penduduk Miskin Menggunakan Algoritma K-Means di Dusun Bagik Endep Sukamulia Timur," Infotek J. Inform. dan Teknol., vol. 4, no. 1, pp. 39-50, Jan. 2021, doi: 10.29408/jit.v4i1.2986.

[11] F. Rahmawati and N. Merlina, "Metode Data Mining Terhadap Data Penjualan Sparepart 
Mesin Fotocopy Menggunakan Algoritma

Apriori," PIKSEL Penelit. IImu Komput. Sist.

Embed. Log., vol. 6, no. 1, pp. 9-20, 2018, doi: 10.33558/piksel.v6i1.1390.

[12] A. Nastuti, "Amelia Nastuti 1 ), Syaiful Zuhri Harahap 2 )," Tek. Data Min. Untuk Penentuan Paket Hemat Sembako Dan Kebutuhan Hari. Dengan Menggunakan Algoritm. Fp-Growth, vol. 7, no. 3, pp. 111119, 2019.

[13] R. Yanto and R. Khoiriah, "Implementasi Data Mining dengan Metode Algoritma Apriori dalam Menentukan Pola Pembelian Obat," Creat. Inf. Technol. J., vol. 2, no. 2, p. 102, 2015, doi: 10.24076/citec.2015v2i2.41.

[14] M. I. Ghozali, R. Z. Ehwan, and W. H. Sugiharto, "Analisa Pola Belanja Menggunakan Algoritma Fp Growth, Self
Organizing Map (Som) Dan K Medoids," Simetris J. Tek. Mesin, Elektro dan IImu Komput., vol. 8, no. 1, pp. 317-326, 2017, doi: 10.24176/simet.v8i1.995.

[15] E. Budiyati, Hurniningsih, and M. D. Lusita, "Implementasi Metode Algoritma Apriori Untuk Penempatan Buku Pada Rak Perpustakaan Stmik Jakarta Sti\&K," J. Inf. Syst. Informatics Comput., vol. 4, no. 1, pp. 30-39, 2020.

[16] N. F. FAHRUDIN, "Penerapan Algoritma Apriori untuk Market Basket Analysis," MIND J., vol. 1, no. 2, pp. 13-23, Jun. 2019, doi: 10.26760/mindjournal.v4i1 